\title{
Identifying the Impact of Temperature and Water Stress on Growth and Yield Parameters of Chilli (Capsicum annuum L.)
}

\author{
M. D. M. Gunawardena and C. S. De Silva* \\ Department of Agricultural and Plantation Engineering, The Open \\ University of Sri Lanka
}

\begin{abstract}
The effect of climate change on global food security has assumed a frightening dimension in developing nations. The need for efficient management to cope with the effect of climate change became imperative. The main aim of this research is to compare the growth and yield parameters of Chilli when it subjected to temperature and water stress. Experiments were conducted on the growing seasons of 2010 and 2011 at the Open University Sri Lanka Agricultural field located at Nawala, Nugegoda using Chilli Varity MI-2 in temperature regulated polytunnels. Split plot experiment based on Completely Randomized Design with 10 replicates was applied as an experimental design. Main plot included two different wetting applications (No water stress-at field capacity level and water stress at $50 \%$ depletion from the field capacity level) and sub plots contained 3 different temperature regimes $\left(34^{\circ} \mathrm{C}, 32{ }^{\circ} \mathrm{C}\right.$ temperature and ambient temperature).
\end{abstract}

According to the results the temperature stress has especially affected the plant height, branches, canopy diameter and number of fruit weight at 0.01 probability levels. Further temperature stress showed significant effect at 0.05 probability level on transplant success, fruit diameter and number of fruits per plant. According to the yield parameters it was observed that interaction effect of the stresses of temperature and water had higher significant impact on growth and yield of Chilli. Yield reduction of Chilli due to temperature stress can be overcome by providing water at field capacity level of the soil moisture during growing period.

Keywords: soil moisture, temperature stress, water stress, growth parameters, yield parameters

* Correspondence should be addressed to Professor C. S. De Silva, Dept. of Agricultural \& Plantation Engineering, Faculty of Engineering Technology, The Open University of Sri Lanka (email: csdes@ou.ac.1k) 


\section{Introduction}

One of the most fundamental questions facing humanity today is global warming and how the humanity will face it with respect to increase food production. Up to now model-based research on climate impact on regions dominated by agriculture mostly deals with yield development, landscape water balance, nutrient dynamics and nutrient loads or endangerment of habitats separately. Higher temperature in next decades implies higher evaporation and therefore higher water demand for the crops will be expected. The phenological development rates of the crops will increase due to the higher temperature and an increase of temperature as well as water stress can be expected.

Fernando and Chandrapala (1996) showed that the amount of rainfall received by the country has been declining gradually. For example, the average annual rainfall which amounted to $2005 \mathrm{~mm}$ during 1931-1960 had declined to $1861 \mathrm{~mm}$ during the more recent (1961-1990) period. Long term temperature trends reveal a rise in temperature by $0.016{ }^{\circ} \mathrm{C}$ per year in 14 Meteorological stations during the recent 30 year period (Fernando and Chandrapala, 1992). Punyawardana (2002) reiterates that an increase in temperature in Sri Lanka would affect the high value vegetable and potato cultivation in the central hill country and the cool season potato and other vegetables cultivation in the Jaffna peninsula, if night time minimum temperatures continue to increase. Consequently yield per unit area would be lower; resulting in an increase in the water demand of rain fed and irrigated crops as well as an increase in the potential evapotranspiration.

\section{Justification of this study}

Studies in Sri Lanka based on HadCM3 general circulation model has revealed that the temperature will increase in coming years and in 2050s the highest temperature increase by $2^{\circ} \mathrm{C}$ in predicted in Anuradhapura compared to the baseline temperature of 19611990 (De Silva 2006). The rainfall during northeast monsoon is predicted to decrease in dry zone area. Therefore the decreased rainfall and increased in temperature will increase the evapotranspiration and soil moisture deficits. Agricultural activities in the dry zone may be affected by predicted climate change in Sri Lanka (De Silva et. al., 2007). Therefore this 
research aimed to determine the effect of high temperature and water stress on growth, yield and quality parameters of Chilli variety MI-2.

Chilli (Capsicum annuum L.) has its unique place in Asian diet a spice as well as a vegetable. It is also a high value crop commercially grown in Sri Lanka. Chilli is grown as a mono crop in most of the dry zone areas and the harvest can be sold as fresh or dried. Because dry chilli fetches high prices, farmers used to dry their harvest and to sell it when the prices are high. Due to these farmers grow Chilli in large extents. With the growing concerns of climate change with varying temperature and water stresses, it is important to study how Chilli plants behave under high temperature and water stress conditions. This study is focused to understand the impact on growth and yield parameters of Chilli when exposed to temperature and water stress conditions and to suggest possible adaptation measures.

\section{Methodology}

The study was conducted at the Open University Sri Lanka, Nawala, Nugegoda from September 2009 to April 2011 for the consecutive 3 seasons. The cultivar MI-2 of Chilli was used in this study; this cultivar is currently recommended by the Department of Agriculture for production in Sri Lanka. All the plants were planted in pots filled with reddish brown earth (Figure 1).

\section{Simulated environmental conditions}

Polytunnels were constructed in order to maintain the stipulated temperature conditions by means of thermostat and air circulation fans (Figure 2). One set of polytunnel was maintained at $32{ }^{\circ} \mathrm{C}$ maximum temperature. And the other set of polytunnel was maintained at $34{ }^{\circ} \mathrm{C}$ upper limit through out the growing seasons. When the temperature increases above the respective maximum temperature, the fans starts to operate until the temperature is controlled to the maximum temperature fixed by the thermostat for that particular polytunnel. 


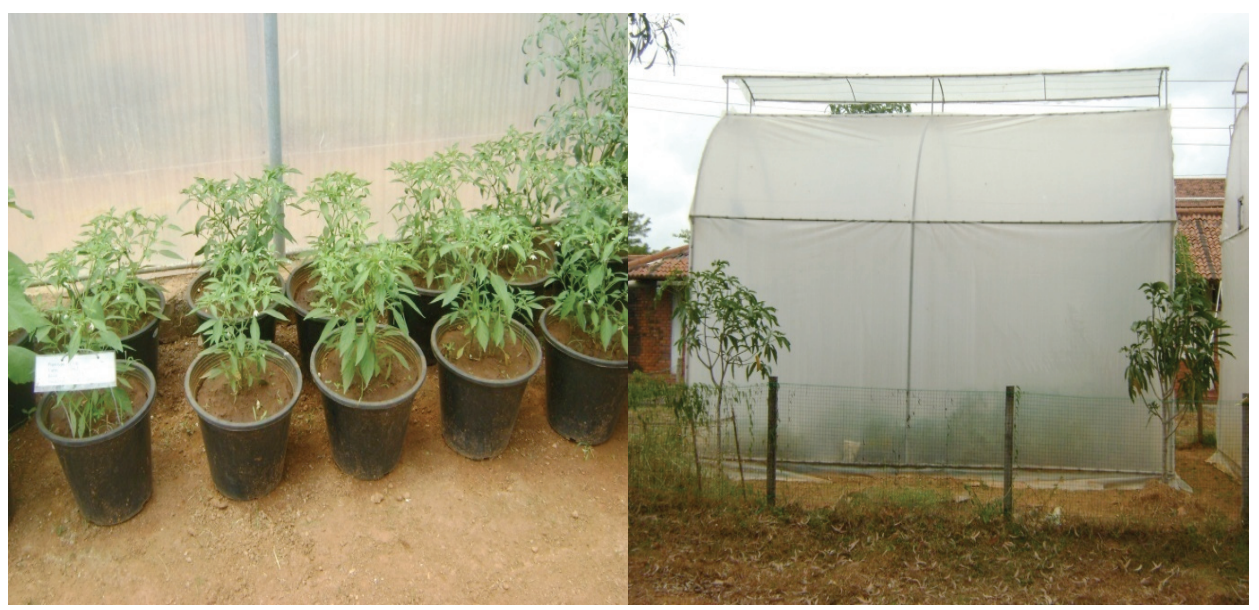

Figure 1. Pots arrangement

Figure 2. Poly tunnels

\section{Experimental Designing}

The experiment was laid out in split plot experiment based on completely randomized design with ten replicates for the main plot treatment. Main plot included two different soil moisture conditions such as field capacity (no water stress) and $50 \%$ of the field capacity level (with imposed water stress) and sub plots containing 3 different temperature regimes such as $34{ }^{\circ} \mathrm{C}$ maximum temperature poly tunnel, $32{ }^{\circ} \mathrm{C}$ maximum temperature poly tunnel and ambient temperature at open space. Soil moisture measurements were carried out using tensiometer. The soil water content in half of pots was kept at field capacity by compensating the loss in weight by adding water. Physiological and morphological parameters of Chilli were investigated during the growing and reproductive periods.

Chilli was raised in a nursery and transplanting was conducted 4 weeks after planting (4WAP). According to the Figure 3 half of Chilli plants in each temperature block were subjected to water stress until they reached relative soil water content (RWC) of $50 \%$. It was done using the Soil tensiometer. In the open space (Ambient temperature) cultivation with water stress and without water stress were practiced as a control. Further in the open space the water stressed plants were under the cover so that 50\% soil moisture depletion could be maintained. Regular management 
practices (Fertilization, weeding etc.) were adopted except water management.

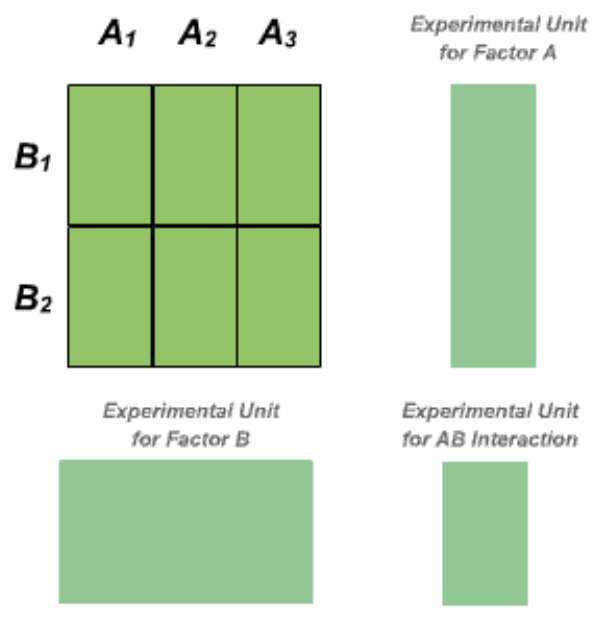

Figure 3. Experiment lay out

Periodic non-destructive measurements were carried out on the same plants to monitor the effects of temperature, and water stress on shoot growth. As for the plant physiological parameter measurements, plant height was measured from the shoot apex down to the base at the soil surface level, pod length were measured using measuring ruler, pod diameter was determined using vernier calliper while number of pods per plant and number of leaves per plant was counted.

The number of leaves on the main stem (primary leaves) and the rest of the leaves on the shoots subtending the primary flowers which were longer than $1 \mathrm{~cm}$ (secondary leaves) were counted and totalled to determine effects on leaf initiation. The measurements included the total numbers of flowers and flower buds and the time required to reach anthesis or abscission. From these observations, the percentages of flowers abscising or reaching pod setting were calculated. Average weight was determined of matured green fruits from the second harvest. Measurements were taken weekly till the end of the growing season. 


\section{Statistical Analysis}

All extraction runs and analyses were carried out at least in duplicate and in randomized order with the mean values being reported. Analysis of variance (ANOVA) of the results was performed using General Linear Model procedure of SPSS (Software Version 19). Multiple comparison of the various means were carried out by LSD (Least Significant Difference) test at P = 0.05 and $\mathrm{p}=0.01$.

\section{Result and Discussion}

\section{Temperature control inside the polytunnels}

Figure 4 shows the variation of temperature inside the poly tunnel and the ambient temperature outside over a period of 24 hours. Even though the sensors and exhaust fans used to maintain temperature inside the poly tunnels the temperature during night time falls below the maximum temperature set for that particular poly tunnel. However, the temperature maintained inside the polytunnels was always higher than the ambient temperature; therefore temperature stress was imposed on the plants throughout the day.

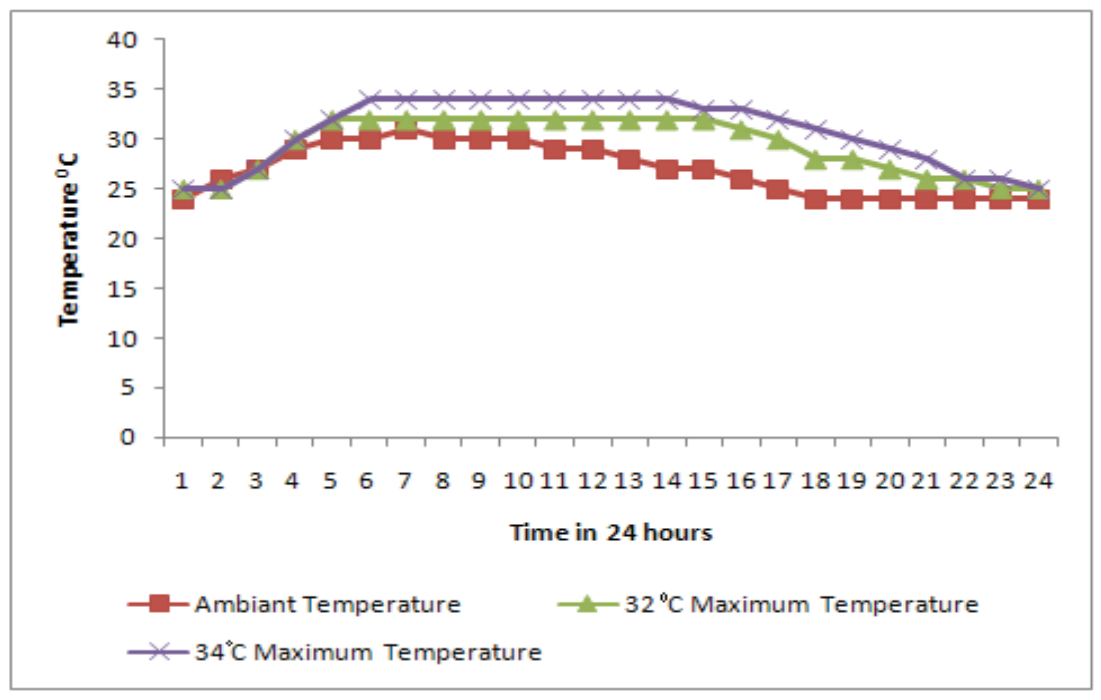

Figure 4. Average Temperature variations inside and outside the poly tunnels within a day 


\section{Temperature and water stress on the growth parameters of Chilli}

\section{Transplant success and shoot growth}

Abiotic and biotic stresses cause alterations in the normal physiological processes of all plant organisms, including the economically important crops. Plant damage and decrease in their productivity take place due to naturally occurring unfavourable factors of the environment such as extreme temperatures, water deficit. Analysis of variance showed significant difference for most of the characters (Table 2) both individual stresses as well as combined stress.

The highest transplant success $(98 \%)$ was reported at $32{ }^{\circ} \mathrm{C}$ maximum temperature polytunnel without a water stress condition (Figure 5). Chilli MI-2 is a dry zone cultivar and which has high plant vigour. Although it has good vigour it shows highly significant $(\mathrm{P}=0.01)$ effect of individual water stress on transplant success and individual temperature stress also showed significant influence at 0.05 probability levels. Lowest transplanting percentage was shown at the $34{ }^{\circ} \mathrm{C}$ maximum temperature combined with the water stressed and this interacting effect also highly significant at the 0.01 probability level. However, interactive effects of the both temperature and water stresses were showed critical effect for the survival after transplanting. Interactive stress effect may reduce the probability of plants establishment because of the effect of high temperature results in low soil water conditions, and that affect on survival of young plants.

\section{Plant height and canopy diameter}

Average plant height among the treatments ranged from $28-70 \mathrm{~cm}$ (Table 1) and generally, a reduction in height is the plant's first response to water stress giving highly significant $(\mathrm{P}=0.01)$ negative growth with the individual water stress effect. Further the average of the three seasons mean results shows that individual temperature stress has highly significant $(\mathrm{P}=0.01)$ positive growth effect on the plants under the indoor condition. It is interesting to notice this interaction effect of both temperature and water stresses severely and negatively affect for the plant growth

(Figure 6). 


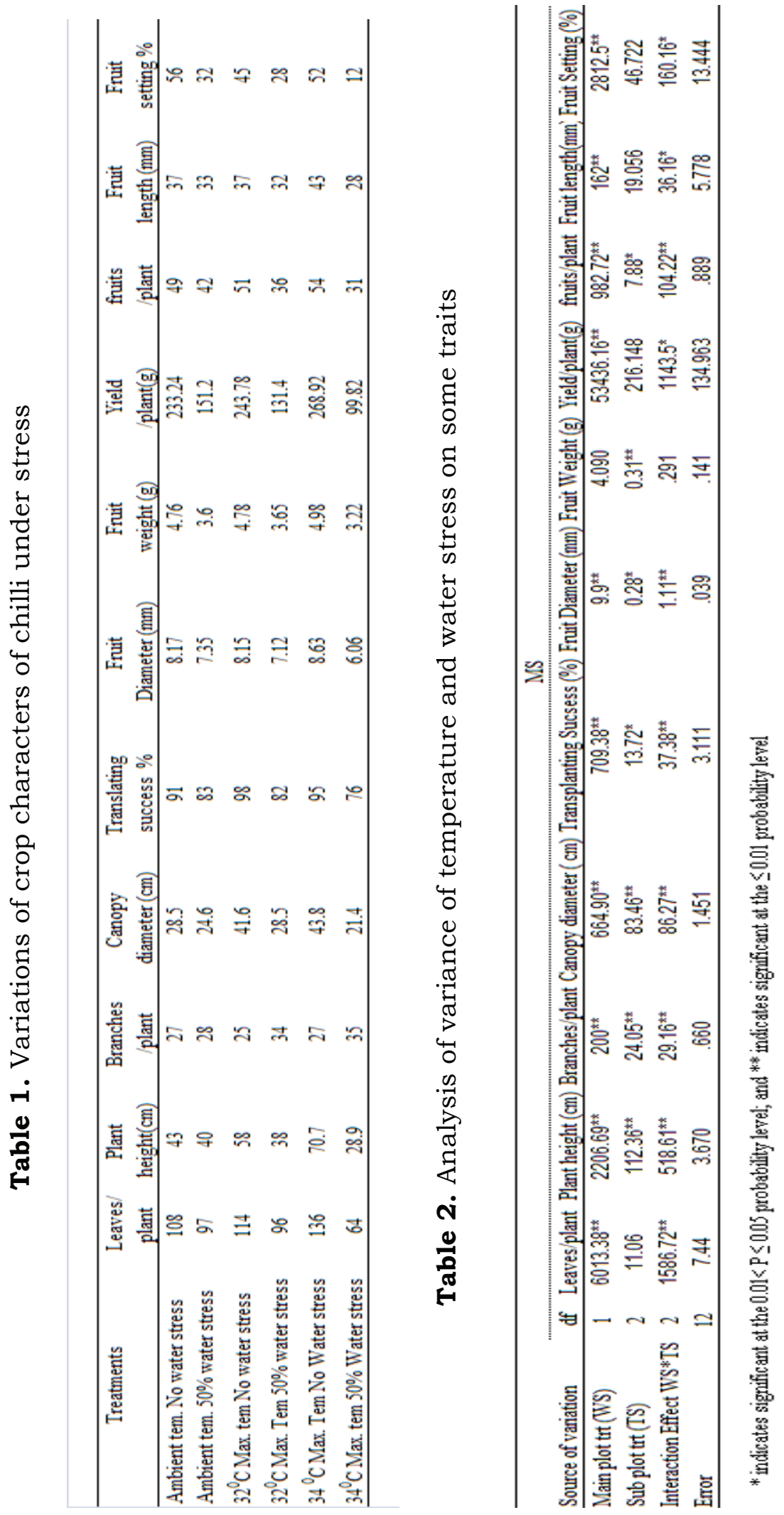




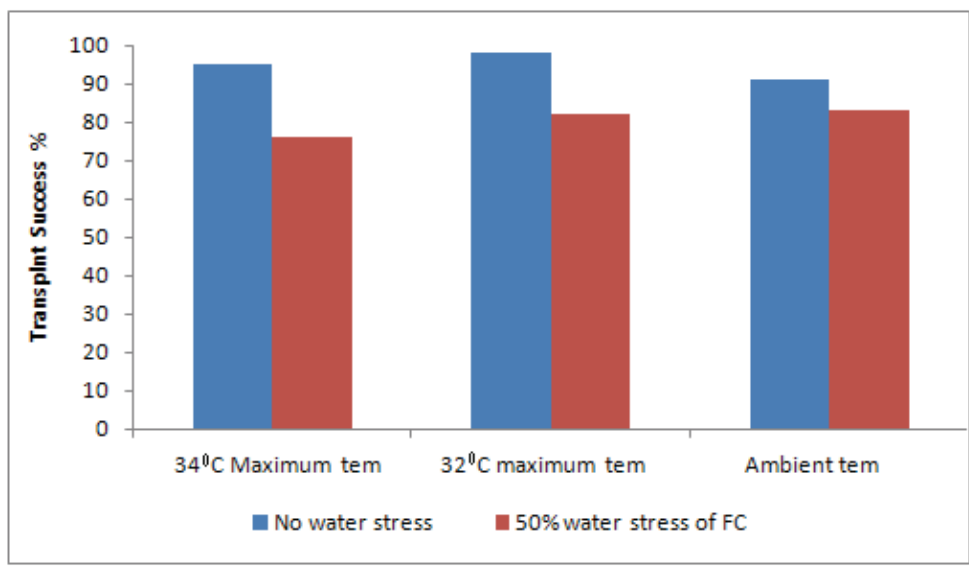

Figure 5. Effect of treatments on average percentage of transplant success

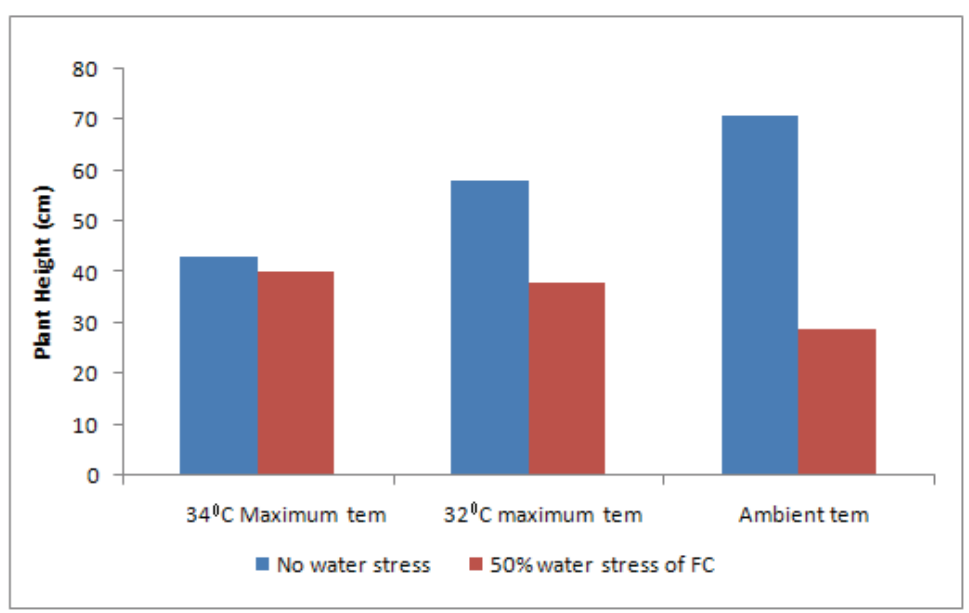

Figure 6. Effect of treatments on average plant height

For the canopy width, the $34^{\circ} \mathrm{C}$ maximum temperature no water stress treatment shows significantly $(\mathrm{P}=0.05)$ highest comparative to the other treatments (Figure7). Yield value indicting a well spread canopy, which contributes directly to the yield. 


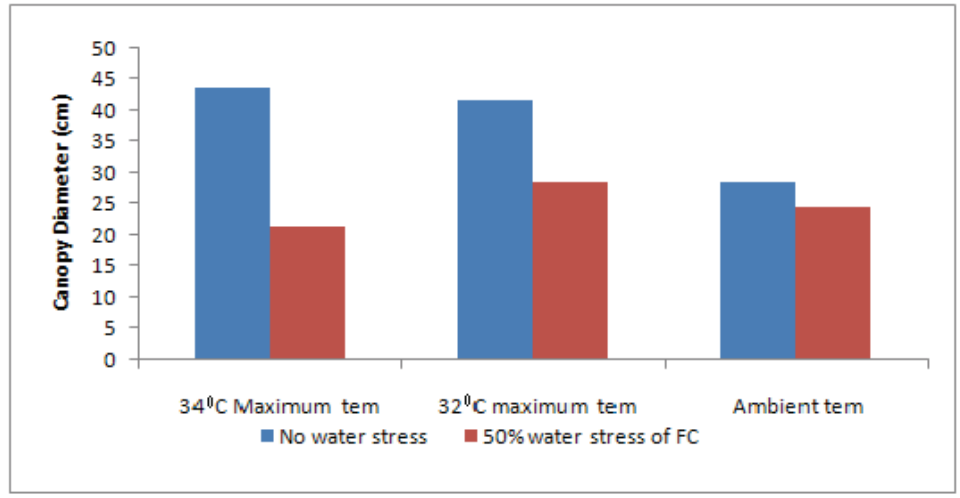

Figure 7. Effect of treatments on canopy diameter

\section{Branches and leaves production of the plant}

Total leaf number (Primary and secondary) was significantly affected by individual water stress effect and interaction between water stress and temperature stress. The highest number of leaves was recorded at $34{ }^{\circ} \mathrm{C}$ maximum temperature under no water stress conditions (136 leaves plant"), whilst only 64 leaves plant" were produced at $34{ }^{\circ} \mathrm{C}$ and water stressed condition and which was the greatest retardation due to the both temperature and water stress effect (Figure 8). Analysis of variance was proved that individual water stress had significantly $(\mathrm{p}=0.01)$ affected the leaf production and interaction effects of both temperature and water stress also showed the same effect. But the results show that there is no significant effect of temperature stress only on the production of leaves.

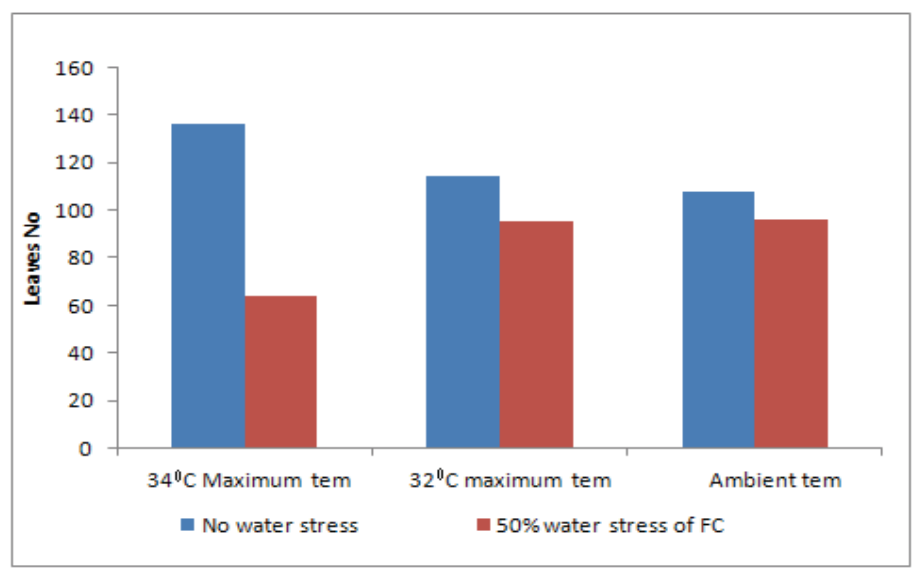

Figure 8. Average number of leaves production 
Average branch production among the 6 treatments is shown in the Figure 9. According to the statistical analysis it is clearly shown that water stress and interaction effect of the water and temperature stress stimulate significantly $(\mathrm{P}=0.01)$ the branch production. But the temperature stress alone negatively affect on branch production. It is well documented that expansion growth is extremely sensitive to water stress (Hsiao et al., 1985; Hsiao and Jing, 1987) and that restriction in leaf expansion is one of the first symptoms of water stress (Kirkham, 1990).

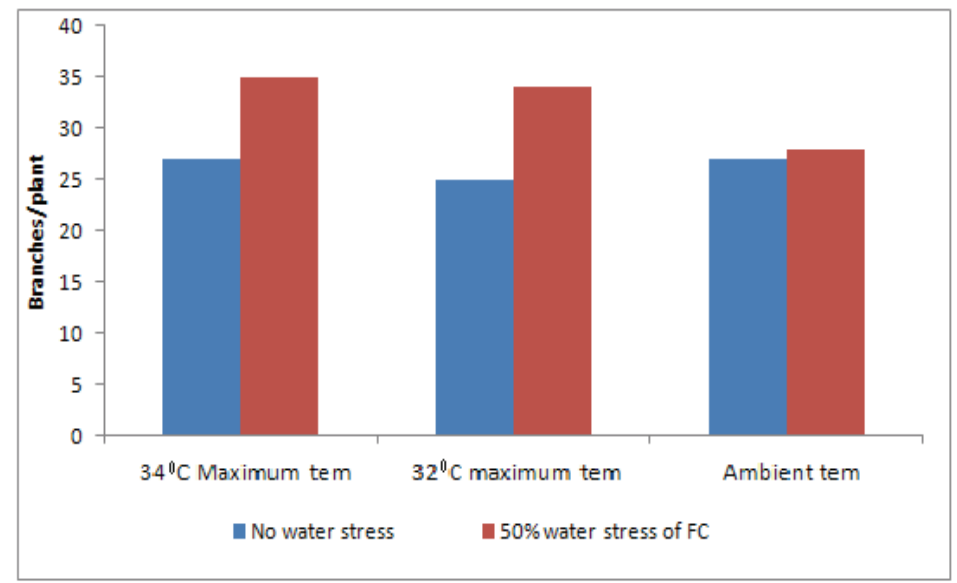

Figure 9. Average branch productions

\section{Temperature and Water stress on yield parameters of Chilli}

\section{Flowering and setting of the fruits}

Flowering of Chilli variety MI-2 was obtained at 6 week after planting and continued for a period of 3 months. Flowering at 34 ${ }^{\circ} \mathrm{C}$ maximum temperature in water stressed treatment took place 8 days earlier than the other treatments. Emergence of the first primary flower bud was accelerated more by the combination of high temperature $\left(34{ }^{\circ} \mathrm{C}\right)$ and water stress. High temperatures generally increase the rate of flower development, resulting in earlier anthesis (Kinet et al., 1985). Plants which were exposed to high temperature and water stress completed its life cycle much faster than other treatments. In determinate annual species warmer temperatures increase the rate of ontogenetic development and results in substantial shortening of the growth 
period. This results in less time for carbon fixation and biomass accumulation before seed set (Pinter et al. 1996, Morison 1996).

In our study Chilli plants under went considerable variation in the number of flowering which set fruits under different treatment conditions (Table 1). Here maximum fruit setting was shown in the ambient temperature no water stress condition and individual water stress was shown highly significant $(\mathrm{P}=0.01)$ effect on the fruit setting. Our study statistically showed that fruit setting did not differ significantly among the temperature treatments. The adverse effect of high temperatures after anthesis is also well illustrated by greenhouse-grown sweet pepper (Song et al. 1976) as the percentage abscission increased with complete abscission of flowers and buds when exposed to $35{ }^{\circ} \mathrm{C}$. In our study interaction stresses showed significant reduction of fruit setting at 0.01 probability level. Gopalaratnum (1933) was observed that high temperature, low soil moisture and low atmospheric humidity were responsible for a low percentage of set fruit.

\section{Number of pods per plants and pod yield}

The number of fruit is an important yield component of Chilli to achieve highest yield. According to Table 2 water stressed condition had significantly $(\mathrm{p}<0.01)$ affected the number of fruits per plant. Further the Figure 10 shows that the highest temperature stress with adequate soil moisture at field capacity level has increased the number of fruits per plant compared to the other treatments significantly $(\mathrm{p}<0.01)$. The highest number of fruits per plant (6.6) was found with high temperature $\left(34{ }^{\circ} \mathrm{C}\right)$ with no water stress treatment and which was followed by $32{ }^{\circ} \mathrm{C}$ temperature with no water stress condition. The number of fruits per plant was lowest when Chilli was subjected to water stressed conditions. Drought occurring during vegetative growth period is called as vegetative phase drought. This type of drought affects plant's assimilatory organs, which usually decrease in number and size resulting in lower photosynthates production (Kaiser, 1987; Chaves, 1991; Larcher, 1995; Chaves et al. 2002). As a result yield decreases due to less amount of assimilate available to the developing pods.

However it is interesting to note that even the highest temperature and water stress has lowest number of fruits per plant compared to other water stressed treatments. It shows that the combination stress effects of temperature and water have 
higher negative effects on number of fruits per plant in Chilli compared to the individual water stress treatments.

The fresh fruit yield is the most important character when considering the economic importance of this crop. These results showed that individual water stress had highly significant $(\mathrm{P}<$ $0.01)$ negative effect on production on the plants. Similar results were obtained byAde-Ademiluae.al. (2009) in his study because there is a direct relationship between quantity of water used by the crop and yield.

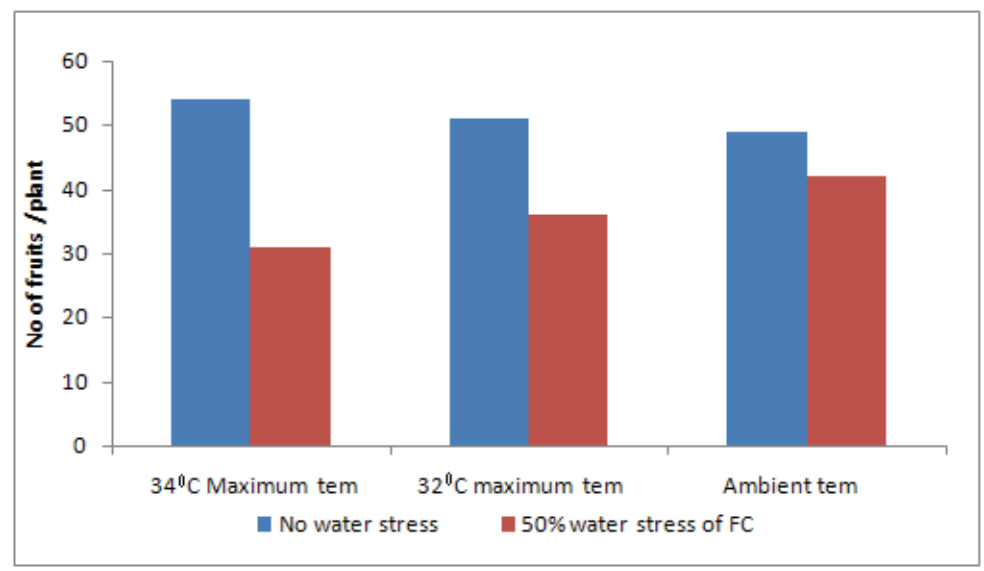

Figure 10. Effect of treatments on average no of fruits/plant

There is no significant reduction of mean yield when Chilli plants grown in high temperature $\left(34^{\circ} \mathrm{C}\right)$ condition without water stress condition (Figure 11). According to Table 1 Chilli yield can be improved under high temperature $\left(34{ }^{\circ} \mathrm{C}\right)$ by giving adequate water for the plant growth. Although Chilli plants shows significant yield reduction with combined stress effect, overall yield can be recovered from the damage caused by temperature stress by providing water to maintain the soil moisture at the field capacity level.

Fruit length and individual fruit weight were higher (Table 1) in the plants grown under high temperature $\left(34{ }^{\circ} \mathrm{C}\right)$ condition under no water stress condition. The highest number of fruits per plant was shown when plants grown at $34^{\circ} \mathrm{C}$ maximum temperature condition without water stress. Generally the yield of Chilli grown under $34{ }^{\circ} \mathrm{C}$ temperature was $(292 \mathrm{~g} /$ plant $)$ which is higher than the other treatments. The lowest significant yield was observed in high temperature polytunnel $\left(34^{\circ} \mathrm{C}\right)$ under $50 \%$ water stressed 
condition. According to the results, the interaction between high temperature and water deficit affects the yield of Chilli than the individual stress of either temperature or water. Similarly Delatorre (2008) demonstrates that interaction between high temperature and water deficit affects photosynthesis responses greater than the individual stresses. In high temperature conditions the negative influence of environmental stresses such as water stress will be exacerbated and the current vegetation and yield may undergo major drawbacks (Centritto et al., 1999c; Centritto, 2002).

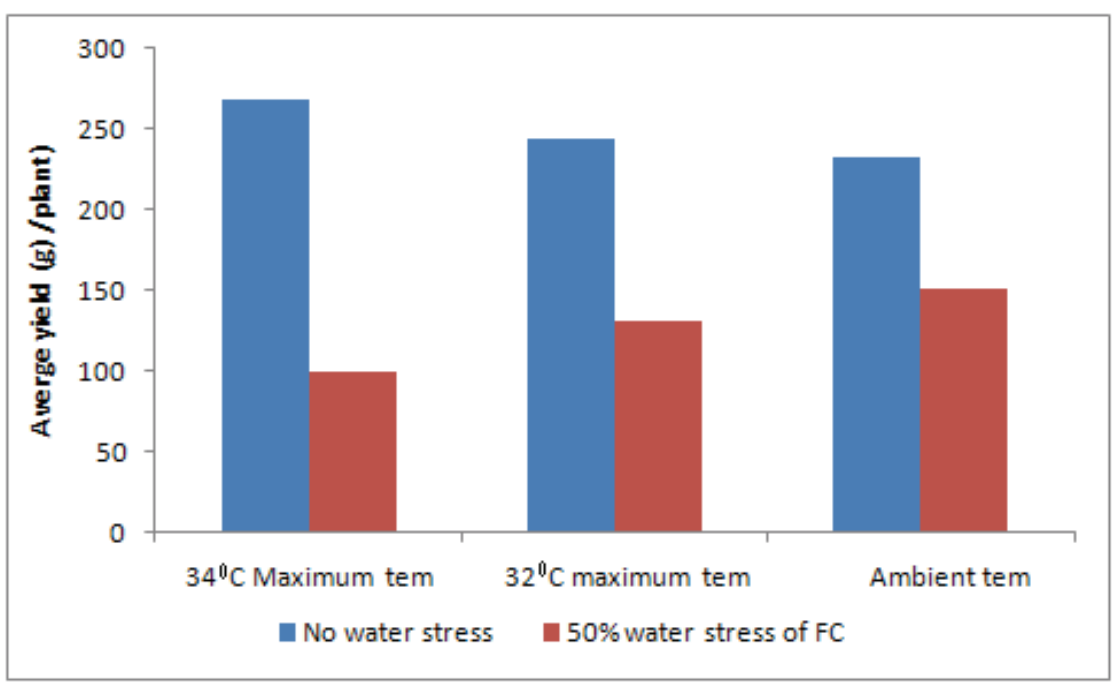

Figure 11. Effect of treatments on average plant yield

\section{Fruit diameter and fruit length}

When plants were exposed to $34{ }^{\circ} \mathrm{C}$ maximum temperature and no water stress condition the diameter of the pods were rapid in growth and reached the maximum. Both individual stress as well as the interactive stress has high significant influence $(p<0.01)$ on the pod diameter (Figure 12).

The fresh pod length was affected significantly $(\mathrm{p}<0.01)$ in individual water stress. The interactive stress effect significantly reduces the fruit length on the 0.05 probability level (Table 1 and Figure 13). 


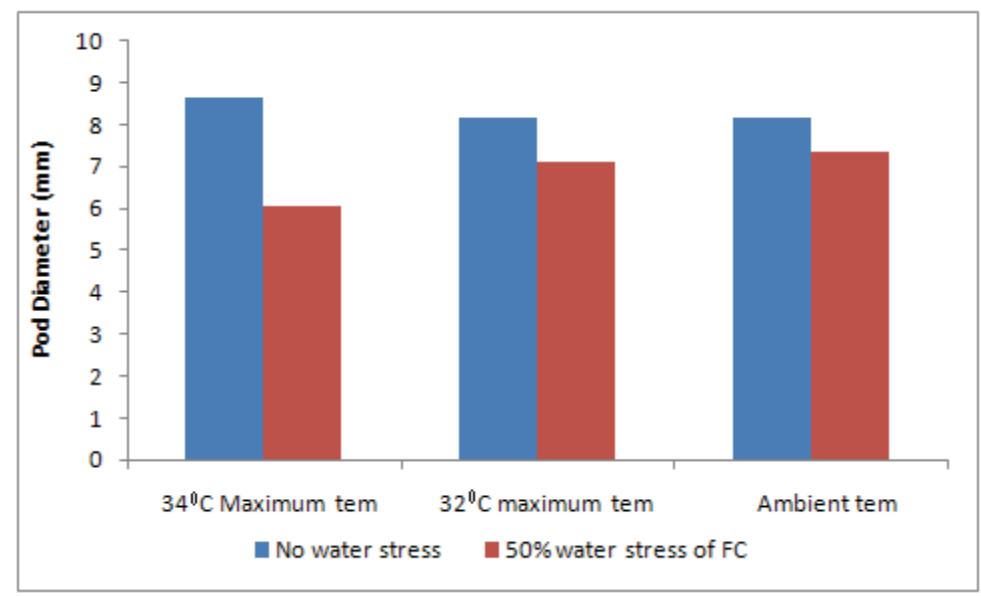

Figure 12. Effect of treatments on fruit diameter

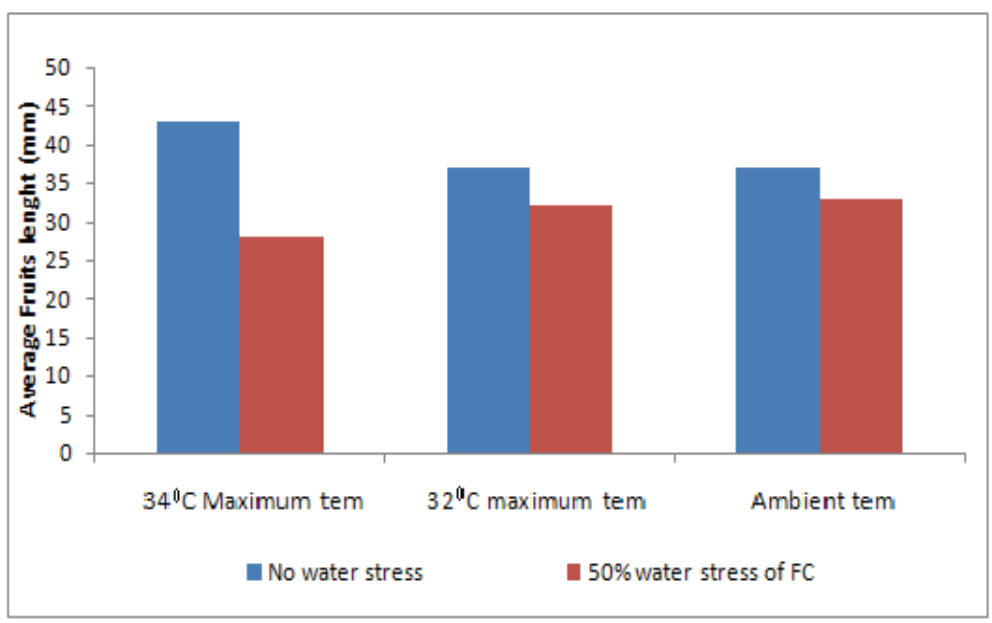

Figure 13. Effect on treatments on fruit length

\section{4 fruit weight}

The treatments (Table 1$)$ are highly significant on the $(p<0.01)$ fresh and dry weight of Chilli pods under individual water stresses. In the case of dry matter of the fruit the maximum weight was observed at the $34{ }^{\circ} \mathrm{C}$ temperature with no water stress condition. Even the combined effect of high temperature $\left(32{ }^{\circ} \mathrm{C}\right)$ and water stress had the remarkable effect on the fruit weight of Chilli compared to the other treatments (Figure 14). 


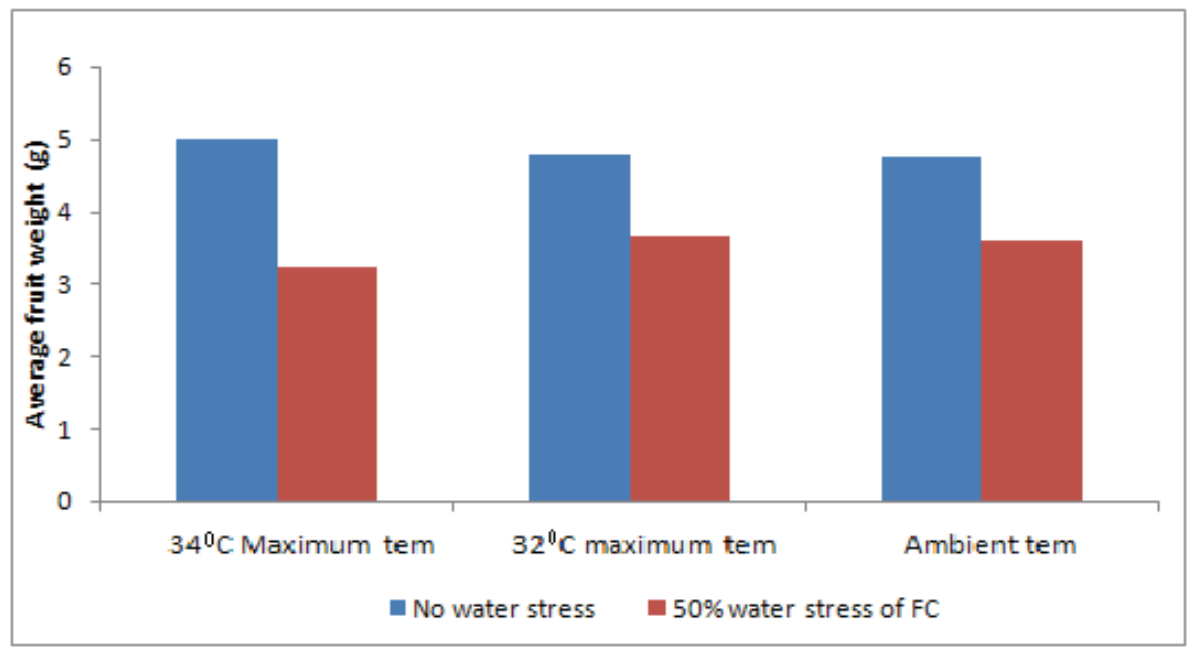

Figure 14. Effect of treatments on average fruit weight

\section{Conclusion}

The sustenance of Chilli production to Sri Lanka is very important to improve agricultural productivity with the future changing climate. From the study, it was observed that interaction effect of the stresses of temperature and water had higher significant impact on growth and yield of the Chilli crop. The Chilli variety MI2 could be identified from this field experiment for water stress tolerance and survival. Yield reduction of Chilli due to temperature stress can be overcome by providing adequate water to the plants without water stress in the soil zone during growing period. This study might serve to understand the adaptation applicability for in the context of global warming.

\section{Acknowledgements}

Authors acknowledge the National Science Foundation for the research grant (RG/2008/AG/04) given to Prof C. S De Silva as Principal Investigator and the first author as a research student. 


\section{References}

Ade-Ademilua, O. E., Iwaotan T. O. \& Osaji, T. C. (2009). Pre planting (cold) treatment of allium sativum cloves improves its growth and yield under open field and open shade conditions. J.Plant Sci., 4, 49-58.

Centritto, M., Lucas, M. E. \& Jarvis, P. G. (2002). Gas exchange, biomass, whole-plant water-use efficiency and water uptake of peach (Prunus persica) seedlings in response to elevated $\left[\mathrm{CO}_{2}\right]$ and water availability. Tree Physiol. 22, 699-706.

Centritto, M., Magnani, F., Lee, H. \& Jarvis P.G. (1999). Interactive effects of elevated $\left[\mathrm{CO}_{2}\right]$ and water stress on cherry (Prunus avium) seedlings. II. Photosynthetic capacity and water relations. New Phytol. 141, 141152

Chandrapala, L. (1996). Long term trends of rainfall and temperature in Sri Lanka. In: Climate variability and agriculture, Abrol, Y.P. Gadgil, S, Pant, G.B. (Eds). New Delhi, India, Narosa publishing house. 153-162.

Chaves, M. M. (1991). Effects of water deficits on carbon assimilation. J. Expt. Bot. 42, 1-16.

Chaves, M. M., Pereira, J.S., Maroco, M.L., Rodrigues, C.P.P., Ricardo, M.L., Osório, I., Carvalho, T., Faria \& Pinheiro,C. (2002). How plants cope with stress in the field: photosynthesis and growth. Ann. Bot. 89, 907916.

De Silva, C. S (2006). Impacts of climate change on potential soil moisture deficits and its use as a climate indicator to forecast irrigation need in Sri Lanka. Water Resources Research in Sri Lanka, Postgraduate Institute of Agriculture, University of Peradeniya., pp79-90, ISBN 955-1308-05-0

De Silva, C. S., E. K. Weatherhead, J. W. Knox, J.A. \& RodrihuezDiaz (2007). Predicting the impacts of climate change-A case study of paddy irrigation water requirements in Sri Lanka. Agricultural Water Management, 93, 19-29. 
Fernando, T. K. \&Chandrapala, L. 1992. Global warming and rainfall variability - Sri Lankan Situation. Proceedings of the 47th annual session of Sri Lanka Association for the Advancement of Science (SLASS). Section E1. P.138

Hsiao, T. C. \& Jing, J. (1987). Leaf and root expansive growth in response to water deficits. In: Physiology of Cell Expansion during Plant Growth. Eds. D. J. Cosgrove and D. P. Knievel, American Society of Plant Physiology, Rockville, MD. pp. 180-192.

Hsiao, T. C., Silk, W. K. \& Jing, J. (1985). Leaf growth and water deficits: Biophysical effects. In: Control of Leaf Growth. Ed. N. R. Baker, (pp. 239- 266). Cambridge University Press, Cambridge.

Kaiser, W. M. (1987). Effects of water deficit on photosynthetic capacity. Physiological Plantarum 71, 142-149.

Kirkham, M. B. (1990). Plant responses to water deficits. In: Irrigation of Agricultural Crops - Agronomy Monograph. Eds. B. A. Stewart and D. R. Nielsen, 323-342.

Kinet, J. M., Sachs, R. M. \& Bernier, G. (1985). The Physiology of Flowering. CRC Press, Boca Raton, Florida, USA.

Larcher, W. (1995). Physiological plant ecology: ecophysiology and stress physiology of functional groups. New YorkBerlin Heidelberg: Springer-Verlag, 506.

Punyawardana, B. V. R. (2002). Climate change: Challenges and opportunities in Sri Lanka, Natural Resource Management Centre, Sri Lanka.

Song, K. W., Park, S. K. \& Kim, C. K. (1976). Studies on the flower abscission of hot pepper. Research report Office, Rural Development, 18, 9-32. 